\title{
A High-Efficiency Bidirectional AC/DC Topology for V2G Applications
}

\author{
Mei $\mathrm{Su}^{*}, \mathrm{Hua}^{*}{ }^{*}$, Yao Sun ${ }^{\dagger}$, and Wenjing Xiong* \\ $\uparrow^{* *}$ Department of Information Science and Engineering, Central South University, Changsha, China
}

\begin{abstract}
This paper proposes a single-phase bidirectional AC/DC converter topology applied in V2G systems, which consists of an inverter and a bidirectional non-inverting buck-boost converter. This topology can operate in four modes: buck charging, boost charging, buck discharging and boost discharging with high input current quality and unity input power factor. The inverter switches at line frequency, which is different from conventional voltage source inverters. A bidirectional buck-boost converter is utilized to adapt to a wider charging voltage range. The modulation and control strategy is introduced in detail, and the switching patterns are optimized to reduce the current ripple. In addition, the semiconductor losses are analyzed. Simulation and experimental results demonstrate the validity and effectiveness of the proposed topology.
\end{abstract}

Key words: Bidirectional AC/DC converter, Semiconductor losses, Single-phase, V2G

\section{INTRODUCTION}

The increasingly serious energy shortage and environmental pollution issues have drawn the attention of relevant authorities to the importance of energy conservation and emission reduction. Developing plug-in hybrid electric vehicles (PHEV) and electric vehicles (EV) is an effective way to solve the above issues [1]-[4]. "V2G" is used generically for both $\mathrm{V} 2 \mathrm{G}$ and $\mathrm{G} 2 \mathrm{~V}$ energy flows: energy stored in a battery returns to the grid to support it at peaks of consumer energy demands, and the energy is transferred from the grid to vehicles via batteries during off-peak periods. Therefore, the $\mathrm{V} 2 \mathrm{G}$ concept improves the performance of the power grid in terms of efficiency, stability and reliability [5]. In the near future, V2G will become an indispensable part of the electric vehicle industry [6]-[8].

Bidirectional battery chargers play a critical role in V2G systems, and they should possess the characteristics of bidirectional power flow, high input current quality, power factor correction or controllable input power factor and a wide output voltage range. A bidirectional AC/DC converter is either integrated into a car (on-board chargers) or accommodated in specially designed EV charging stations

Manuscript received Mar. 27, 2014; accepted Jun. 10, 2014

Recommended for publication by Associate Editor Honnyong Cha.

†Corresponding Author: yaosuncsu@gmail.com

Tel: +86-731-88876070, Fax: +86-731-88876070, Central South Univ.

*Dept. of Information Science \&Eng., Central South University, China (off-board chargers). In terms of household charging, on-board chargers are the preferred configuration. For V2G applications, a topology with high power density, low cost, low volume and low weight is expected [9]-[13].

In the past, single-phase unidirectional AC/DC converters were used as chargers for electric vehicles and were intensively studied. In [14], a single-phase interleaved AC/DC PFC boost converter for PHEV batteries is studied, and other topologies with the same function have been introduced [15]. All of them only boost the voltage. Thus, a chopper circuit needs to be added to obtain a wider output voltage range. Cascaded unidirectional buck-boost converters for PFC are presented in [16], [17]. They possess high input power factor, low input current THD and a wider range of output voltage. However, all of the converters mentioned above can only be used as battery charger. They cannot return the energy stored in the batteries back to the grid because of the unidirectional switches.

A single phase voltage-source-type rectifier cascading a dc-dc converter [18]-[20], is widely used for electric vehicle chargers. This method offers a two-way electrical energy flow and high quality input current. However, its lifespan is limited, because costly and bulky electrolytic capacitors exist in this type of voltage-source converters. An AC/DC converter with a hybrid structure is proposed in [21]. It realizes the bidirectional power flow and buck/boost function by changing the topology. In discharging mode, the full bridge is modulated in PWM mode as a voltage-source 
inverter. Conversely, in charging mode, it works as a diode rectifier bridge. Nevertheless, its topology structure is complex and the related control algorithm is complicated. Meanwhile, the problem of needing electrolytic capacitors still exists.

In this paper, a single-phase bidirectional topology, which supports a bidirectional power flow and can be adapted to wider applications, is proposed as shown in Fig. 1. The full-bridge works as a rectifier in the charging mode or as an inverter switching at the line frequency in the discharging mode. A bidirectional non-inverting buck-boost converter [22], [23] is utilized to enhance the range of the charging voltage and to realize power factor correction (PFC) in collaboration with the full-bridge inverter. According to the switching state combinations of the non-inverting buck-boost converter, the proposed converter allows for four operation modes: buck charging, boost charging, buck discharging and boost discharging.

The paper is organized as follows: Section II introduces the topology and mathematical model of the proposed converter, and the corresponding control and modulation schemes are presented. In Section III, the semiconductor losses of the proposed topology are analyzed. In Section IV, the experimental results are presented. The main points of this paper are summarized in Section V.

\section{SYSTEM CONFIGURATION AND WORKING PRINCIPLE}

\section{A. Proposed Topology}

Fig. 1 shows the proposed topology of a single-phase bidirectional AC/DC converter. It consists of a second-order LC input filter, a full-bridge inverter and a bidirectional non-inverting buck-boost converter. The input filter is used to prevent the high-frequency harmonic currents generated by the converter from propagating into grid. The full-bridge inverter is used to rectify the AC input voltage to a DC voltage and switches at the line frequency. The bidirectional non-inverting buck-boost converter is employed to regulate the charging voltage in a wide range. In addition, power factor correction (PFC) and high input current quality can be realized with the full-bridge inverter.

\section{B. Modeling of the Proposed Converter}

Assume that the system works in continuous mode. According to Fig. 1, the state space average model for the proposed converter is formulated as follows:

$$
\begin{gathered}
L_{g} \frac{d i_{g}}{d t}=u_{g}-u_{c} \\
C \frac{d u_{c}}{d t}=i_{g}-\operatorname{sgn}\left(u_{c}\right) d_{1} i_{L}
\end{gathered}
$$

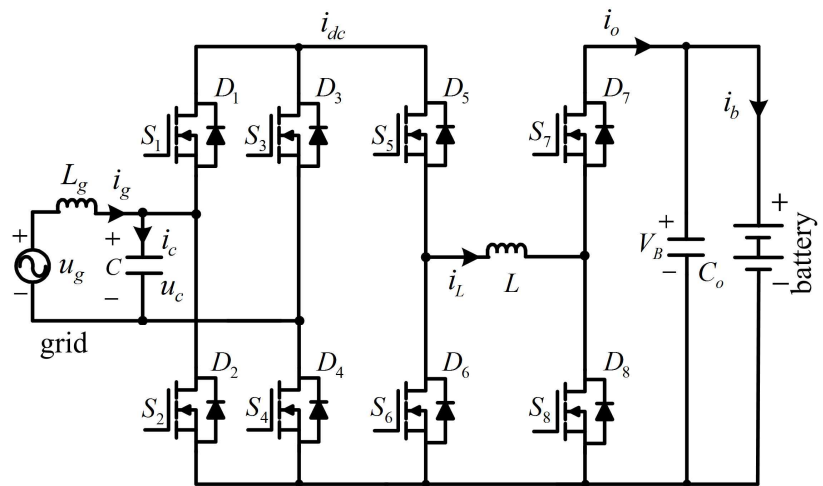

Fig. 1. Proposed topology of single-phase bidirectional AC/DC converter.

$$
L \frac{d i_{L}}{d t}=d_{1}\left|u_{c}\right|-d_{2} V_{B}
$$

where ug is the voltage of the power supply, and $\mathrm{ug}=\mathrm{Vm} \sin (\omega \mathrm{t}) . \mathrm{d} 1$ and $\mathrm{d} 2$ are the duty-cycles of switches S5 and $\mathrm{S} 7$, respectively. $\operatorname{sgn}()$ is the sign function.

As an interface circuit for $\mathrm{V} 2 \mathrm{G}$ applications, the objectives of the proposed converter are twofold: charging or discharging the battery and keeping unity power factor. If the input filter is designed properly, the effect of the input filter can be neglected, then ug $\approx \mathrm{uc}$. To realize unity power factor, it is necessary for sgn(uc)d1iL in (2) to be sinusoidal and in phase with the input voltage i.e.

$$
d_{1} i_{L} \approx I_{m}|\sin (\omega t)|
$$

where $\mathrm{Im}$ is the required amplitude value of the input current. If Im is greater than zero, the converter works in charging mode; vice versa, it works in discharging mode.

In the steady state, according to the volt-second balance, the following is obtained:

$$
d_{1} V_{m}|\sin (\omega t)| \approx d_{2} V_{B}
$$

According to (4) and (5), it is obvious that one degree of freedom is available. Therefore, in theory, there are lots of methods available to accomplish the control task mentioned above. In this context, iL is chosen to be a constant. According to (4), the duty cycles $\mathrm{d} 1$ and $\mathrm{d} 2$ are given as:

$$
\begin{aligned}
& d_{1}=\frac{I_{m}|\sin (\omega t)|}{i_{L}} \\
& d_{2}=\frac{I_{m} V_{m}|\sin (\omega t)|^{2}}{i_{L} V_{B}}
\end{aligned}
$$

The buck mode is defined when $\mathrm{VB}<\mathrm{Vm}$ and $\mathrm{d} 1$ can be either greater or less than $\mathrm{d} 2$ depending on the relationship between ug and VB. Conversely, the boost mode is defined when $\mathrm{VB}>\mathrm{Vm}$ and $\mathrm{d} 1$ is always greater than $\mathrm{d} 2$.

The duty-cycles should meet the constraints:

$$
0 \leq d_{1} \leq 1, \quad 0 \leq d_{2} \leq 1
$$

Then, iL should satisfy the following constraint:

$$
i_{L} \geq \max \left\{I_{m}, V_{m} I_{m} / V_{B}\right\}
$$


In practical application, to increase efficiency, it is recommended that $\mathrm{iL}$ be as small as possible when constraint (9) holds.

\section{Principles of Operation}

Taking the charging mode for example, the switching sequence is arranged as shown in Fig. 2. Such a symmetrical arrangement guarantees that the ripple current through the inductor L is small. Two cases are considered: $\mathrm{d} 1>\mathrm{d} 2$ and $\mathrm{d} 1$ $<\mathrm{d} 2$. All of the MOSFETs in the inverter stage operate at the line frequency and switch according to the polarity of the input voltage. Usually, low ON-resistance MOSFETs are selected to increase efficiency. The switches in the non-inverting buck-boost stage are modulated by PWM, as shown in Fig. 3.

Referring to Fig. 1, Fig. 2 and Fig. 3, the operation principle of the proposed converter can be explained as follows:

State $1(\mathrm{t} 10 \sim \mathrm{t} 11, \mathrm{t} 14 \sim \mathrm{t} 20, \mathrm{t} 20 \sim \mathrm{t} 21$ and $\mathrm{t} 24 \sim \mathrm{t} 30):$ $\mathrm{S} 5$ and $\mathrm{S} 7$ are on. The voltage across inductor $\mathrm{L}$ is expressed as: $\mathrm{uL}=|\mathrm{ug}|-\mathrm{VB}$. When $\mathrm{uL}$ is negative, $\mathrm{iL}$ decreases linearly with a slope of (VB - $|\mathrm{ug}|) / \mathrm{L}$, and the energy from the grid and stored in the inductor is transferred to the battery. When $\mathrm{uL}$ is positive, iL increases linearly with a slope of (|ug VB ) / L, and the energy is transferred from the grid to the inductor and battery.

- $\quad$ State 2 (t11 t12 and t13 t14): S5 and S8 are on, and S6 and S7 are off. The inductor starts to absorb energy from the grid and its current iL increases with a slope of $|\mathrm{ug}| / \mathrm{L}$.

- $\quad$ State 3(t12 t13 and t22 t23): S8 and S6 are on and the inductor current starts wheeling through $\mathrm{S} 8$ and S6. iL remains unchanged if the semiconductor losses are ignored.

- $\quad$ State 4(t21 t22 and t23 t24): S5 and S8 are off, and S6 and S7 are on. The energy in the inductor is transferred to the battery through S6 and S7. During this interval, iL decreases linearly with a slope of VB / L.

In fact, the converter can also work in other modes, and similar analysis method can be applied. Therefore, the details are neglected here.

\section{Control Strategy}

A control block diagram for the proposed converter is shown in Fig.4. It is a classical two-loop control structure including an outer-loop voltage controller and an inner-loop current controller. The outer-loop controller is designed to realize the constant voltage charging, and the feedback signal for $\mathrm{VB}$ is processed by a notch filter to eliminate the negative effect of the double-line frequency ripple voltage. Its output

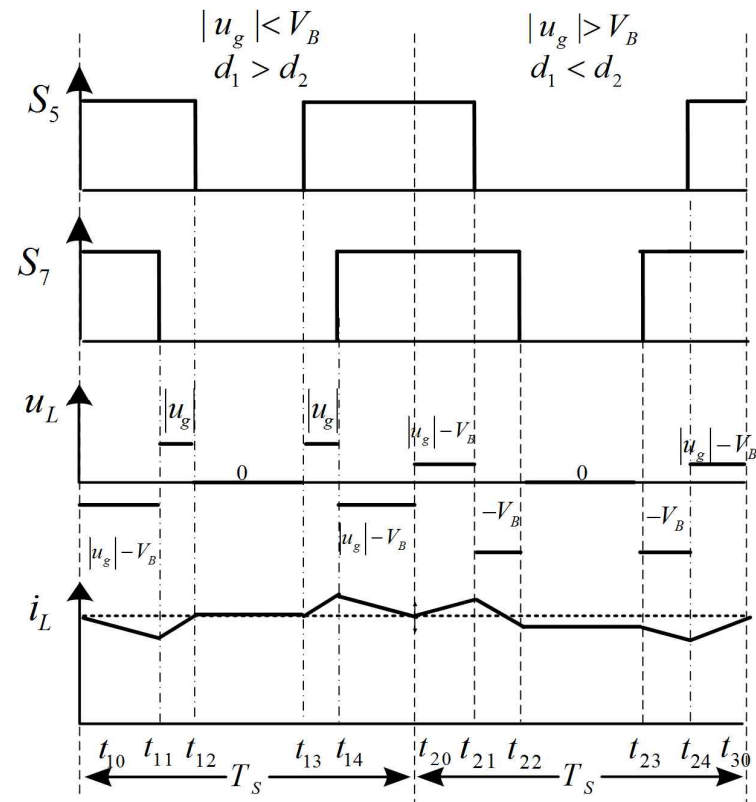

Fig. 2. Waveforms under the double-sided switching pattern.

is the reference current Im for the inner-loop controller. To realize PFC in the inner-loop controller, a simple feed-forward control is adopted. To regulate the current through the inductor, a control scheme including the feed-forward control and the PI feedback control is presented. The feed-forward control directly compensates the effect of the first term on the right side of equation (3). This increases the dynamic response of the current control. The PI controller helps to stabilize the system and to handle some unknown disturbances. In practical applications, the reference of $\mathrm{iL}$ is chosen to be $1.05 \operatorname{Immax}(1, \mathrm{Vm} / \mathrm{VB})$ for power loss consideration and for the assurance of a sufficiently adjustable margin for the switch duty-cycle.

\section{POWER LOSS ANALYSIS}

The power loss calculation of a power converter is crucial, since it can be used to guide the design of the heat sink and to estimate the system efficiency. The power losses can be divided into two parts: semiconductor losses and passive components losses [24]. In the proposed converter, the semiconductor losses are dominant. Therefore, the power loss calculation focuses on the semiconductors in this section. Usually, semiconductor losses include conduction loss and switching loss, which are related to the topology structure, modulation strategy and commutation method [25]. The conduction loss and the switching loss can be formulated as follows [26], [27]:

$$
\begin{gathered}
P_{c_{-} S_{i}}=\frac{1}{T} \int_{0}^{T} u_{D S}(t) i_{D}(t) d t \\
P_{s w_{-} S_{i}}=\frac{f_{s}}{T} \int_{0}^{T}\left[\frac{1}{2} u_{D S}(t) i_{D}(t)\left(t_{o n}+t_{o f f}\right)+\frac{1}{2} C_{o s s} u_{D S}(t)^{2}\right] d t
\end{gathered}
$$



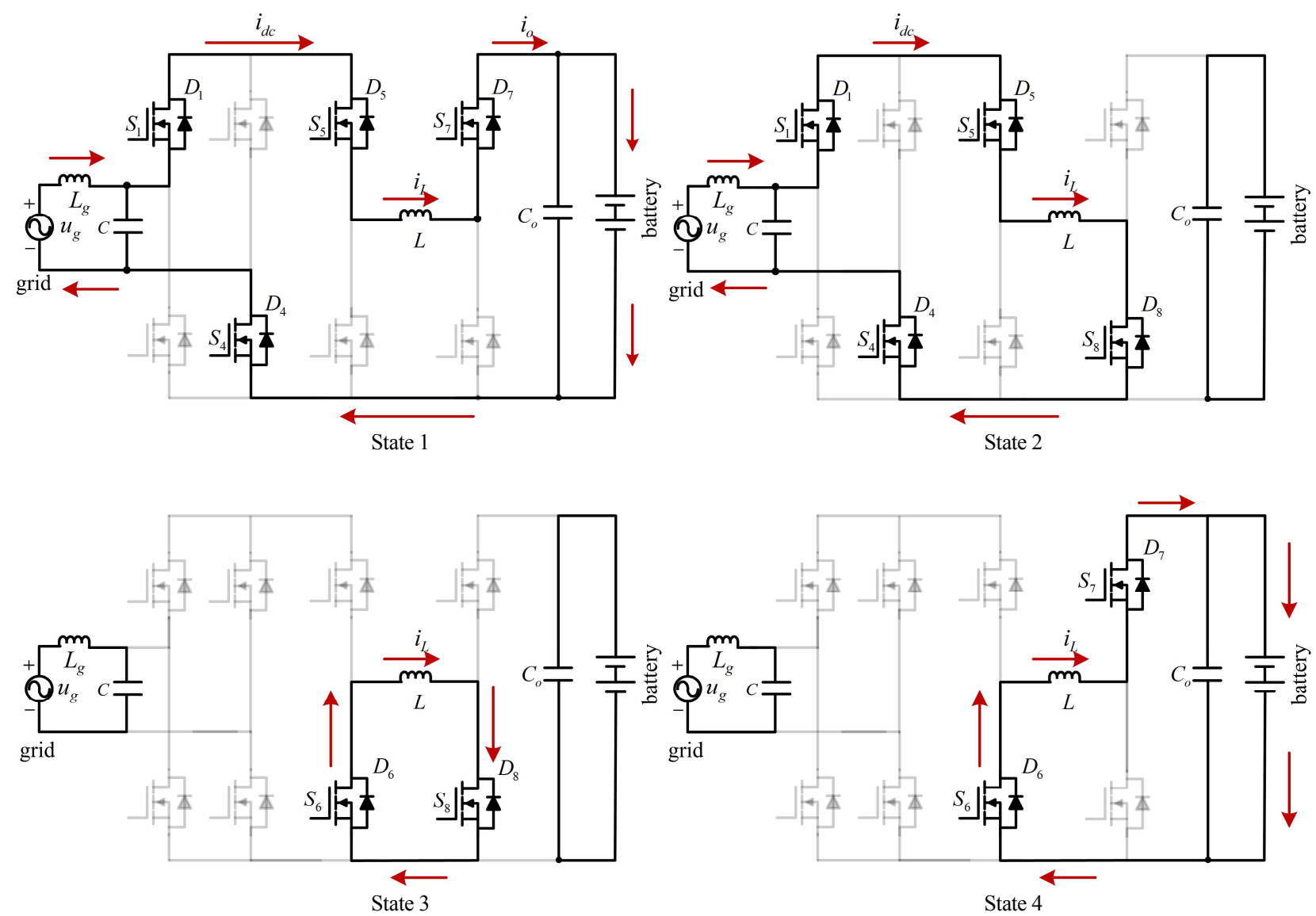

Fig. 3. Analysis of the switching process.

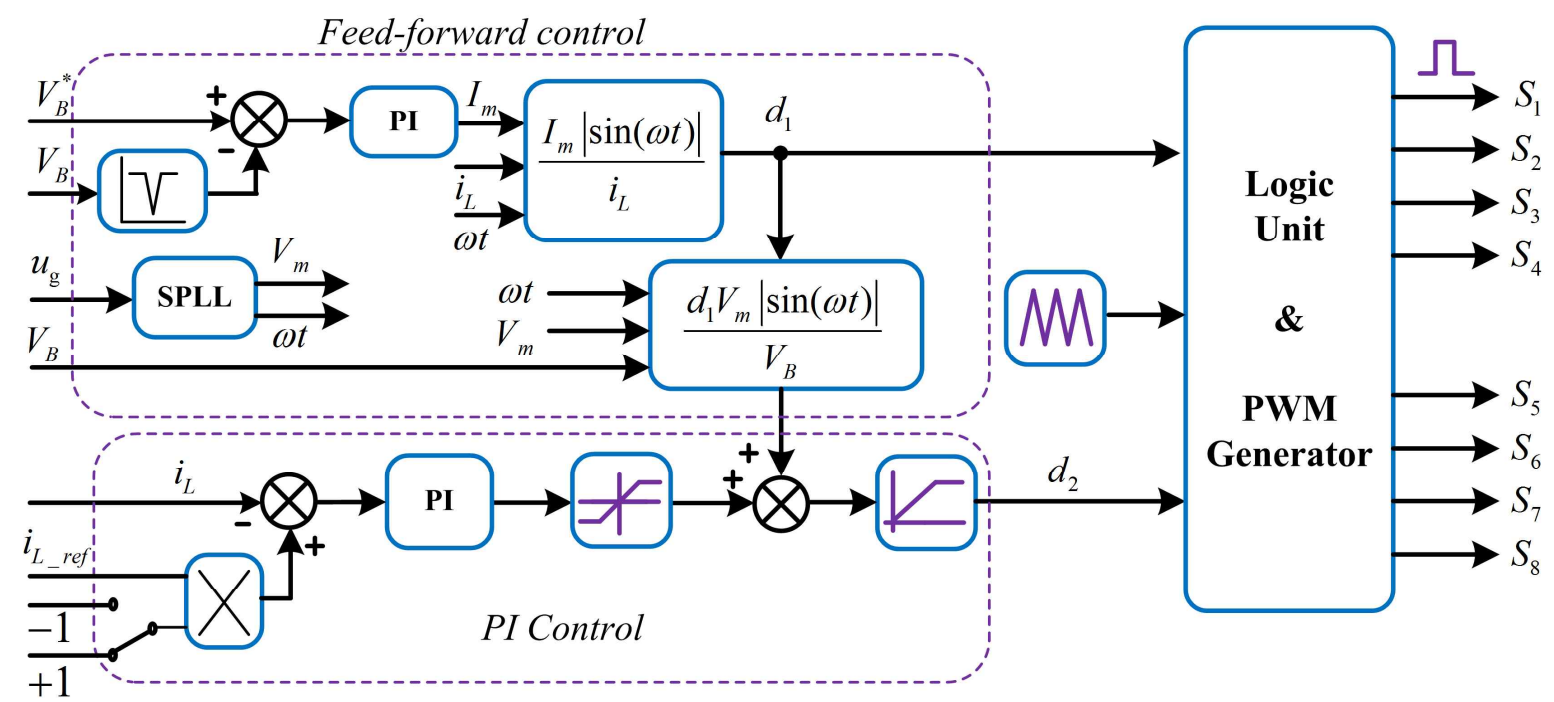

Fig. 4. Control block diagram for the proposed converter.

$$
P_{s w_{-} D_{i}}=f_{s} \frac{1}{T} \int_{0}^{T} Q_{r r} u_{F}(t) d t
$$

where Pc_Si is the conduction loss of the MOSFET, Psw_Si is the switching loss of the MOSFET, Psw_Di is the diode reverse recovery loss, $\mathrm{T}$ is the period of the integrated function, fS is the switching frequency, and $\mathrm{uDS}(\mathrm{t})$ and $\mathrm{iD}(\mathrm{t})$ separately represent the voltage between the source and drain of the switch and the flowing current. Coss is the output capacitor of the MOSFET, Qrr is the diode reverse recovery charge and $\mathrm{uF}(\mathrm{t})$ is the reverse voltage for the diode. According to the datasheet of the MOSFET, the relationship between the conduction voltage drop and flowing current can be approximately expressed as:

$$
R_{D S(o n)}=k i_{D}(t)+b
$$


Thus:

$$
u_{D S}(t)=R_{D S(o n)} i_{D}(t)
$$

the coefficient $\mathrm{k}$ and $\mathrm{b}$ can be determined according to the datasheet of the adopted MOSFET.

According to the control and modulation scheme mentioned above, both the related conduction loss and switching loss will be analyzed as follows. Since the inverter stage switches at the line frequency and the bidirectional conductivity of the MOSFET, the loss of the inverter stage is mainly caused by the conduction loss of the MOSFET. The semiconductor loss related to the non-inverting buck-boost converter includes conduction loss and switching loss. Similarly, the conduction loss of the end stage is mainly caused by the MOSFET since the body diode conducts only during the commutation process in the dead time, and whose loss can be ignored. For the switching loss, take S5 and S6 in the charging mode as an example, and assume the following initial state: S5 is on and S6 is off. The inductor current flows through S5. Then, S5 turns off, and the inductor flows through D6 during the dead region. When the drive signal is added to S6, S6 turns on with zero voltage and no turn-on loss is generated. After a certain time, S6 turns off without a turn-off loss for the same reason. Then, the current path is changed to D6 again. After the dead time, the drive signal is added to S5, and the current path is changed to S5. During this process, the turn-on loss of S5 and reverse recovery loss of D6 are generated. The loss analysis process for the other switches is similar and the details concerning their losses are listed in Table I. In the discharging mode, there is something different. The details about the loss analysis of the buck-boost converter are listed in Table II, where Pon, Poff and Prr represents the turn-on loss, turn-off loss and reverse recovery loss under $\mathrm{v}$ and i, respectively.

Take unity input power factor in the charging mode as an example, the details of the loss calculation are presented as follows.

Suppose that the intermediate inductor current is controlled as a constant:

$$
i_{L_{-} \text {ref }}=I_{L}
$$

For the inverter stage, the loss can be calculated by:

$$
P_{c_{-} i n v_{-} \text {total }}=\frac{4 I_{m} I_{L}\left(k I_{L}+b\right)}{\pi}
$$

For the non-inverting stage, since duty ratio of the upper and lower bridge arm is complementary and the switch parameters are completely consistent, the conduction loss and switching loss could be expressed as:

$$
\begin{aligned}
& P_{c_{-} \text {buck-boost }}=2 I_{L}^{2}\left(k I_{L}+b\right) \\
& P_{S W}= f_{s}\left[I_{L}\left(t_{o n}+t_{o f f}\right)\left(\frac{1}{\pi} V_{m}+\frac{1}{2} V_{B}\right)+\right. \\
&\left.\frac{1}{4} C_{o s s}\left(V_{m}^{2}+2 V_{B}^{2}\right)+Q_{r r}\left(\frac{2}{\pi} V_{m}+V_{B}\right)\right]
\end{aligned}
$$

Thus, the total semiconductor losses of the topology under
TABLE I

The Loss AnAlysis of BuCK-Boost CONVERTER IN CHARging Mode

\begin{tabular}{lcccc}
\hline & $S_{5}$ & $D_{6}$ & $D_{7}$ & $S_{8}$ \\
\hline $\begin{array}{c}\text { Duty ratio } \\
\text { Switching }\end{array}$ & $d_{1}$ & $1-d_{1}$ & $d_{2}$ & $1-d_{2}$ \\
loss & $P_{\text {on }}+P_{\text {off }}$ & $P_{r r}$ & $P_{r r}$ & $P_{\text {on }}+P_{\text {off }}$ \\
Voltage/ $v$ & $\left|u_{g}\right|$ & $\left|u_{g}\right|$ & $V_{B}$ & $V_{B}$ \\
Current $i$ & $i_{L}$ & $i_{L}$ & $i_{L}$ & $i_{L}$ \\
\hline
\end{tabular}

TABLE II

The Loss ANALysis of BUCK-Boost CONVERTER IN DISCHARGING MODE

\begin{tabular}{lcccc}
\hline & $D_{5}$ & $S_{6}$ & $S_{7}$ & $D_{8}$ \\
\hline Duty ratio & $d_{1}$ & $1-d_{1}$ & $d_{2}$ & $1-d_{2}$ \\
Switching & $P_{r r}$ & $P_{o n}+P_{o f f}$ & $P_{o n}+P_{o f f}$ & $P_{r r}$ \\
loss & $\left|u_{g}\right|$ & $\left|u_{g}\right|$ & $V_{B}$ & $V_{B}$ \\
Voltage/ $v$ & $i_{L}$ & $i_{L}$ & $i_{L}$ \\
Current $i$ & $i_{L}$ & & & \\
\hline
\end{tabular}

the presented control schemes can be expressed as the sum of equations (16), (17) and (18):

$$
P_{\text {total }}=P_{c_{-} \text {inv_total }}+P_{c_{-} \text {buck-boost }}+P_{S W}
$$

Actually, the analytical expression for the loss calculation in the discharging mode is identical to that in the charging mode since the duty ratio of the switches and inductor current remain the same. However, the loss distribution is different in both modes.

Obviously, the larger the inductor current iL, the greater the semiconductor losses become according to the foregoing calculation results.

Considering that the peak value of the grid is $90 \mathrm{~V}$, the output voltage of the battery is set to $60 \mathrm{~V} / 120 \mathrm{~V}$, the switch frequency is $20 \mathrm{KHz}$ and a MOSFET (IPB200N25N3) is adopted. The efficiency curves for the analytical calculation and experiments vary with the input power, and are depicted in Fig. 5(a). This figure shows the rough accordance between them. The differences between the results of the analysis and the experiment are mainly caused by the hysteresis loss and eddy-current loss of the inductor, the capacitor loss and other un-modeled losses. As for the bidirectional AC/DC converter, the experimental results above indicate that the efficiency of the proposed topology is very high. As can be seen from Fig. 5 (a), when the input power is relatively small, the efficiency increases with the input power. Conversely, it decreases when the input power is larger. It is clear that the system efficiency depends directly on the battery voltage, the input current or the inductor current. In most cases, the efficiency in boost mode is higher than that in buck mode, since the inductor current is selected to be smaller. From Fig. 5(b), the 


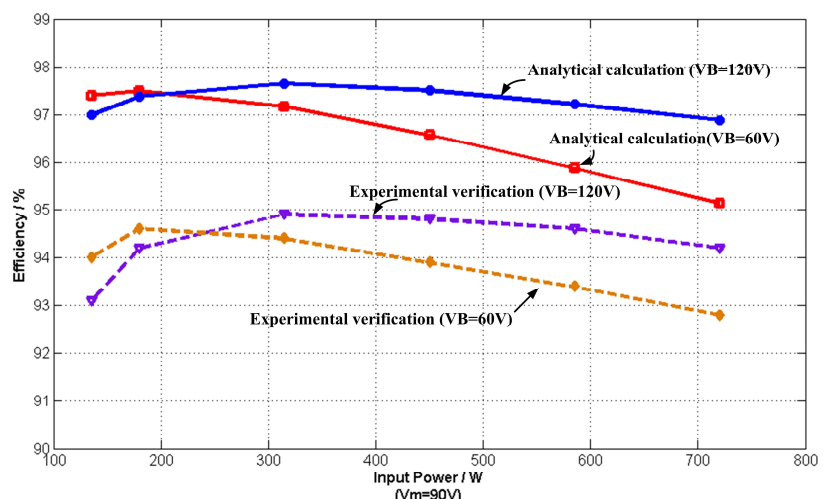

(a)

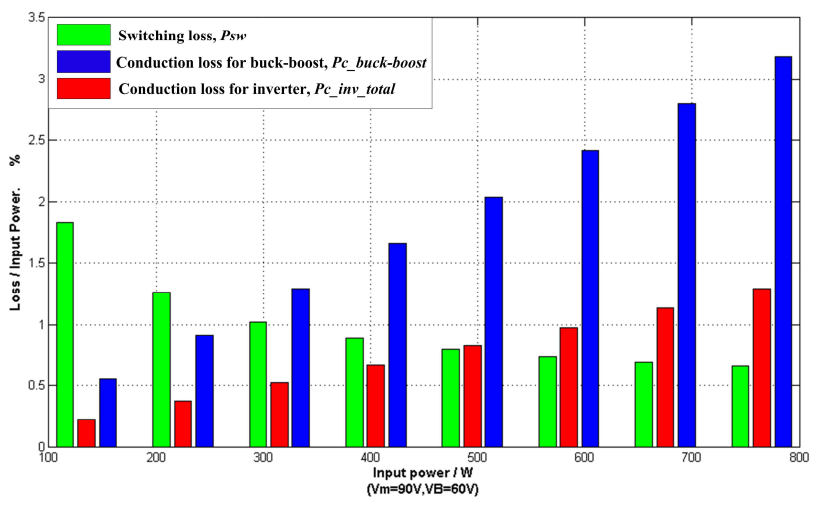

(b)

Fig. 5. System efficiency curve in charging mode. (a) Comparison of the measured and the calculated efficiency for different input power. (b) Loss distribution.

switching loss almost dominates the total loss when the input power is less than $200 \mathrm{~W}$. However, with an increase of the input power, the proportion of the switching loss is smaller and the conduction loss becomes larger.

\section{Simulation AND EXPERIMENTAL Results}

\section{A. Simulation Results}

To validate the proposed method, simulations based on the Matlab/Simulink environment are implemented in this section. The models of the semiconductor device and battery are from the SimPowerSystem / Power Electronics library. The schematic diagram of the converter used in the simulation is shown in Fig. 1, and the parameters of the converter used in the simulation are set to be $0.1 \mathrm{omhs}$ and the diode forward voltage is set to be $0.7 \mathrm{~V}$.

To show the validity of the topology over a wide range of output voltage, two sets of battery voltages are exemplified: $V_{\mathrm{B}}=60 \mathrm{~V}$ and $V_{\mathrm{B}}=120 \mathrm{~V}$.

The simulation results in four different modes are shown in Fig. 6. From top to bottom, the waveforms are the input voltage $u_{\mathrm{g}}$, the grid current $i_{\mathrm{g}}$, the inductor current $i_{\mathrm{L}}$, the battery voltage $V_{\mathrm{B}}$ and the duty ratio $d_{1}$. In the charging mode,
TABLE III

Parameters USED For Proposed Converter Simulation

\begin{tabular}{cc}
\hline Parameters & Value \\
\hline Peak value of input voltage $\left(V_{m}\right)$ & $90 \mathrm{~V}$ \\
Input filter inductor $(L)$ & $0.4 \mathrm{mH}$ \\
Input filter capacitor $(C)$ & $10 \mathrm{uF}$ \\
The intermediate DC inductor $\left(L_{o}\right)$ & $0.6 \mathrm{mH}$ \\
Output filter capacitor $\left(C_{o}\right)$ & $100 \mu \mathrm{F}$ \\
Switching frequency $\left(f_{s}\right)$ & $20 \mathrm{kHz}$ \\
Battery voltage $\left(V_{B}\right)$ & $60 \mathrm{~V} / 120 \mathrm{~V}$ \\
\hline
\end{tabular}

the grid currents are in phase with the input voltages, while in the discharging mode, the input currents and grid voltages are out of phase by $180^{\circ}$. Meanwhile, the THD in the input current is less than $3 \%$ in all of the modes. Interestingly, the inductor current is distorted near the grid voltage zero-crossing region in all of the charging modes, though it is designed to be controlled as a constant value. This happens because the forward voltage drops of the MOSFETs and diodes make the inductor current lose control when the input voltage is small. Though the inductor current is distorted, it does not affect the input current due the real-time compensation of the duty-cycle $d_{1}$. In theory, the waveform of the duty-cycle $d_{1}$ is similar to that of $d_{1}$ in the discharging mode. However, it is distorted in the zero-crossing region. It is increased to compensate the inductor current drop. In the discharging mode, the inductor current is controlled well with less distortion. This is because the inductor current is always in control even in the presence of the voltage drops from the semiconductor devices. It can also be found that the charging voltage is controlled well, and that the voltage ripple is less than $0.5 \mathrm{~V}$.

\section{B. Experimental Results}

A single-phase bidirectional AC/DC converter prototype is built in the lab for experimental verification, as shown in Fig. 7. The parameters are same as those used in the simulation. The power switches used in the main circuit are IPB200N25N3, and the control of the converter is realized by a general control board which is a combination of a digital signal processor TMS320f28335 and a Field Programmable Gate Array (FPGA) EP2C8T144C8N.

Two groups of lead-acid battery packs are used in this experiment. Their specifications are 60V/20Ah and 120V/20Ah. Fig. 8 shows the experimental waveforms of the grid voltage, input current, inductor current and battery voltage in the buck charging mode when a lead-acid battery pack of $60 \mathrm{~V} / 20 \mathrm{Ah}$ is connected to the converter. The inductor current is well tracked except for the zero-crossing region of the grid voltage due to the existence of the forward voltage of the MOSFETs and diodes. As can be seen from Fig. 8, the 

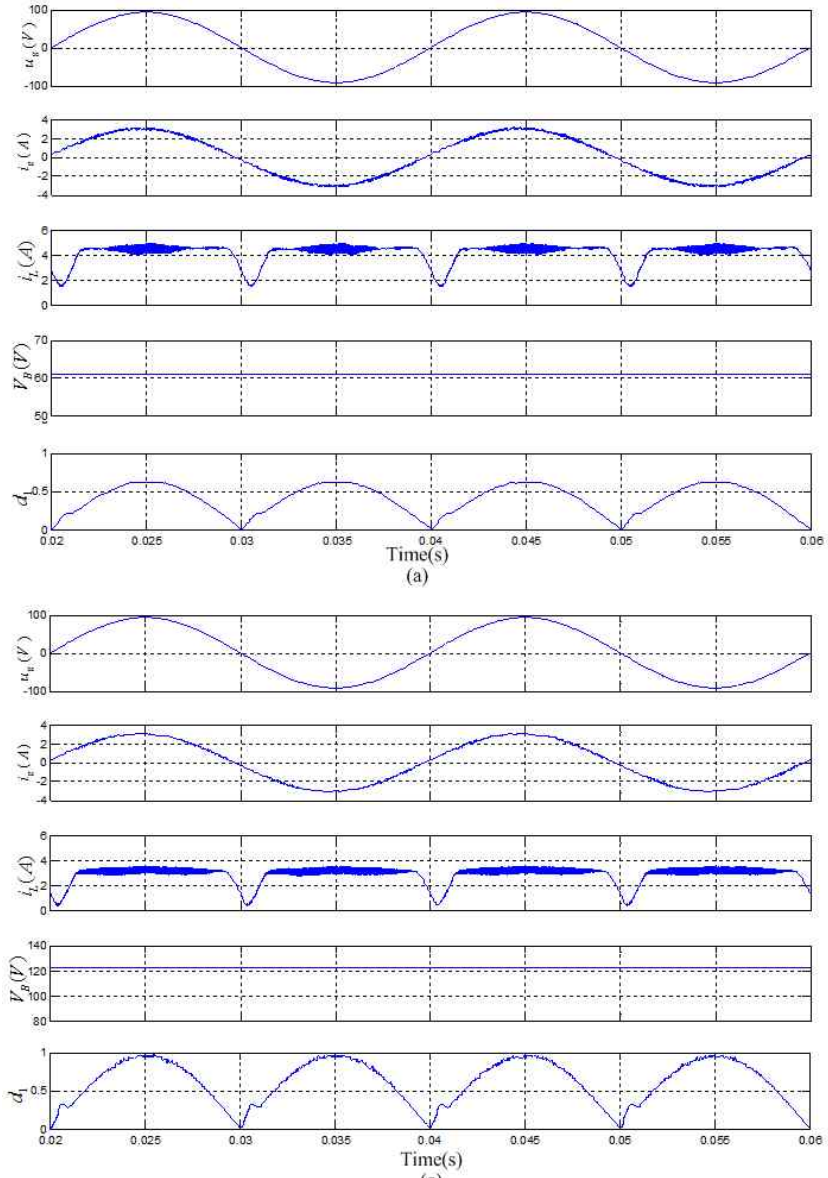

(c)
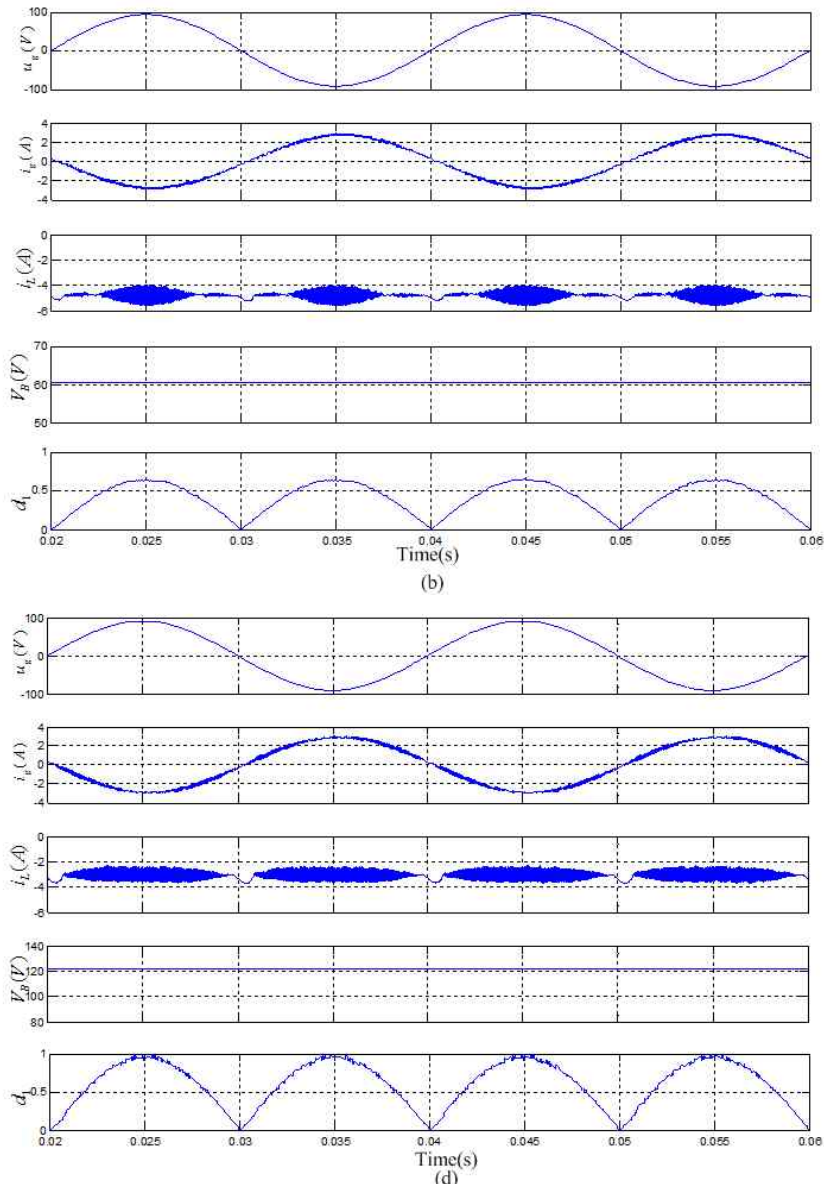

Fig. 6. Simulation results. (a) Buck charging $\left(V_{B}=60 V\right)$. (b) Buck discharging $\left(\left(V_{B}=60 V\right)\right)$. (c) Boost charging $\left(V_{B}=120 V\right)$. (d) Boost discharging $\left(\left(\mathrm{V}_{\mathrm{B}}=120 \mathrm{~V}\right)\right)$.

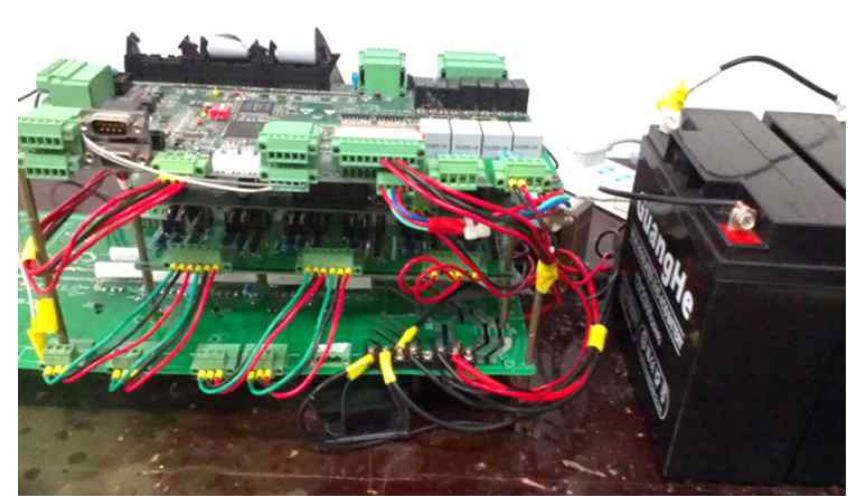

Fig. 7. Prototype of proposed converter built in the laboratory.

battery voltage is controlled well as with only a $0.5 \mathrm{~V}$ voltage ripple. In addition, the THD of the input current is $4.3 \%$ and its input power factor is 0.991 . It is clearly illustrated that the input current is sinusoidal and in phase with the input voltage (unity power factor operation). To transmit energy back to the power grid, the converter should operate in the discharging mode. Fig. 9 shows the relevant waveforms in the buck discharging mode. Compared to Fig. 8, it can be seen that the inductor current is well tracked, and that the phase difference between the input current and the grid voltage is almost $180 \mathrm{o}$.

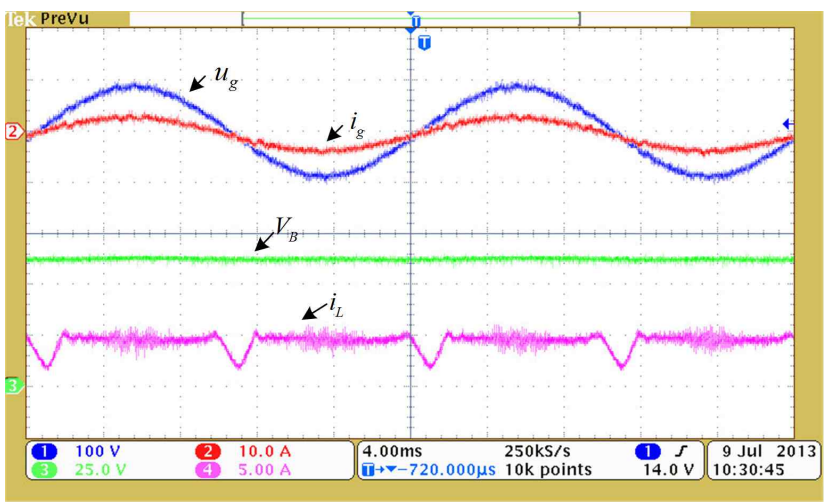

Fig. 8. Experimental converter waveforms in buck charging mode $\left(\mathrm{V}_{\mathrm{B}}=60 \mathrm{~V}\right)$.

Fig. 10 and Fig. 11 show the waveforms in the boost charging and boost discharging mode when a lead-acid battery pack of $120 \mathrm{~V} / 20 \mathrm{Ah}$ is connected to the converter. As can be seen, the experimental results above in all of the modes are in good agreement with the simulation results. It can be concluded that the high quality input current and high performance of the charging and discharging are easily obtained in all modes. 


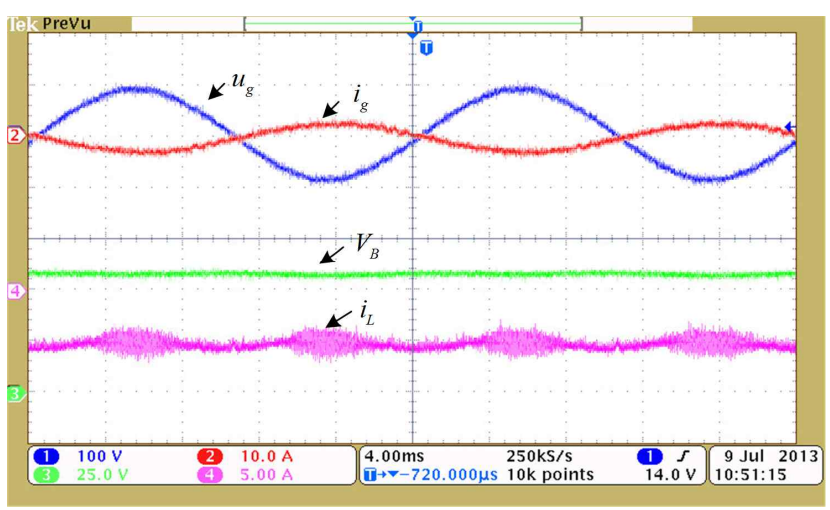

Fig. 9. Experimental converter waveforms in buck discharging mode $\left(V_{B}=60 V\right)$.

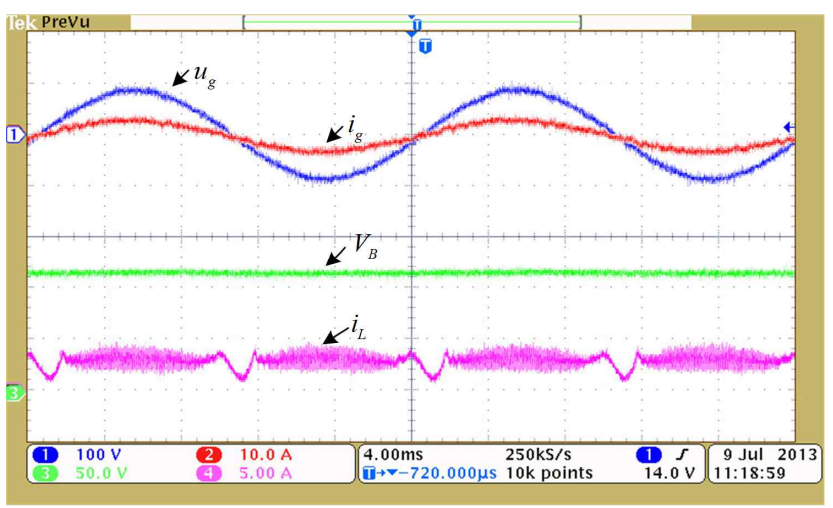

Fig. 10. Experimental converter waveforms in boost charging mode $\left(\mathrm{V}_{\mathrm{B}}=120 \mathrm{~V}\right)$.

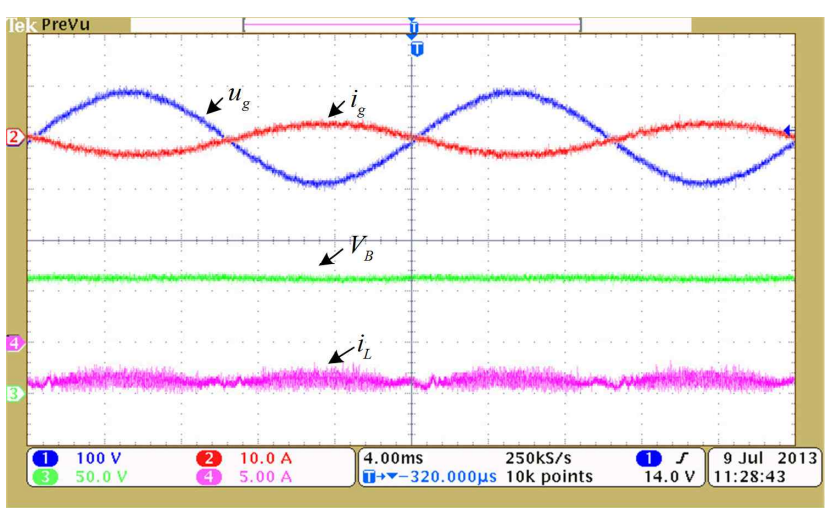

Fig. 11. Experimental converter waveforms in boost discharging mode $\left(\mathrm{V}_{\mathrm{B}}=120 \mathrm{~V}\right)$.

\section{CONCLUSIONS}

In this paper, a single-phase bidirectional AC-DC converter topology, which is well suited to be used as an interface in a V2G, system is proposed. It is a converter with multi-functions including buck charging, buck discharging, boost charging and boost discharging. The mathematical model and operation principles are analyzed in detail. The related control strategy, based on the classical two-loop control structure including an outer-loop voltage controller and an inner-loop current controller, is briefly introduced. The semiconductor losses are also analyzed in detail. The simulation and experimental results verify the proposed method and validate the high quality of the input current and the unity power factor operation.

\section{ACKNOWLEDGMENT}

This work was supported by the Hunan Provincial Natural Science Foundation of China under Grant 14JJ5035 and the National Natural Science Foundation of China under Grant No. 61174125.

\section{REFERENCES}

[1] M. Ceraolo, A. di Donato, and G. Franceschi, "A general approach to energy optimization of hybrid electric vehicles," IEEE Trans. Veh. Technol., Vol. 57, No. 3, pp. 1433-1441, May 2008.

[2] J. A. P. Lopes, F. J. Soares, and P. M. R. Almeida, "Integration of electric vehicles in the electric power system," in Proce. IEEE, pp. 168-183, 2011.

[3] A. Emadi, Y. J. Lee, and K. Rajashekara, "Power electronics and motor drives in electric, hybrid electric, and plug-in hybrid electric vehicles," IEEE Trans. Ind. Electron., Vol. 55, No. 6, pp. 2237-2245, Jun. 2008.

[4] Z. Amjadi and S. S. Williamson, "Power-electronics-based solutions for plug-in hybrid electric vehicle energy storage and management systems," IEEE Trans. Ind. Electron., Vol. 57, No. 2, pp. 608-616, Feb. 2010.

[5] B. Kramer, S. Chakraborty, and B. Kroposki, "A review of plug-in vehicles and vehicle-to-grid capability," Industrial Electronics, 2008. IECON 2008. 34th Annual Conference of IEEE, pp. 2278-2283, 2008.

[6] N. D. Weise, K. K. Mohapatra, and N. Mohan, "Universal utility interface for plug-in hybrid electric vehicles with vehicle-to-grid functionality," Power and Energy Society General Meeting, 2010 IEEE, pp. 1-8, 2010.

[7] W. Kempton and J. Tomić, "Vehicle-to-grid power fundamentals: calculating capacity and net revenue," Journal of Power Sources, Vol. 144, No. 1, pp. 268-279, Jul. 2005.

[8] V. V. Viswanathan and M. Kintner-Meyer, "Second use of transportation batteries: maximizing the value of batteries for transportation and grid services," IEEE Trans. Veh. Technol., Vol. 60, No. 7, pp. 2963-2970, Sep. 2011.

[9] B. Singh, B. N. Singh, A. Chandra, K. Al-Haddad, A. Pandey, and D. P. Kothari, "A review of single-phase improved power quality AC-DC converters," IEEE Trans. Ind. Electron., Vol. 50, No. 5, pp. 962-981, Oct. 2003.

[10] A. Khaligh and S. Dusmez, "Comprehensive topological analysis of conductive and inductive charging solutions for plug-in electric vehicles," IEEE Trans. Veh. Technol., Vol. 61, No. 8, pp. 3475-3489, Oct. 2012.

[11] H. Han, Y. Liu, Y. Sun, H. Wang, and M. Su, "A single-phase current-source bidirectional converter for V2G applications," Journal of Power Electronics, Vol. 14, No. 3, pp. 458-467, May 2014. 
[12] M. Su, H. Wang, Y. Sun, J. Yang, W. Xiong, and Y. Liu, "AC/DC matrix converter with an optimized modulation strategy for V2G application," IEEE Trans. Power Electron., Vol. 28, No. 12, pp. 5736-5745, Dec. 2013.

[13] Y. Sun, W. Liu, M. Su, X. Li, H. Wang, and J. Yang, “A unified modeling and control of a multi-functional current source-typed converter for V2G application," Electric Power Systems Research, Vol. 106, No. 2, pp. 12-20, Jan. 2014.

[14] Y. Jang, and M. M. Jovanovic, "Interleaved boost converter with intrinsic voltage-doubler characteristic for universal-line PFC front end," IEEE Trans. Power Electron., Vol.22, No.4, pp: 1394-1401, Jul. 2007.

[15] F. Musavi, W. Eberle, and W. G. Dunford, "A high-performance single-phase bridgeless interleaved PFC converter for plug-in hybrid electric vehicle battery chargers," IEEE Trans. Ind. Appl., Vol. 47, No. 4, pp. 1833-1843, Jul. 2011.

[16] M. C. Ghanem, K. Al-Haddad, and G. Roy, "A new control strategy to achieve sinusoidal line current in a cascade buck-boost converter," IEEE Trans. Ind. Electron. Vol. 43, No. 3, pp. 441-449, Jun. 1996.

[17] O. Lopez, L. Garcia De Vicuna, M. Castilla, J. Matas, and M. Lopez, "Sliding-mode-control design of a high-power-factor buck-boost rectifier," IEEE Trans. Ind. Electron., Vol. 46, No. 3, pp. 604-612, Jun.1999.

[18] M. C. Kisacikoglu, B. Ozpineci, and L. M. Tolbert, "Effects of V2G reactive power compensation on the component selection in an EV or PHEV bidirectional charger," Energy Conversion Congress and Exposition (ECCE), pp. 870-876, 2010.

[19] O. Onar, J. Kobayashi, and A. Khaligh, "A fully-directional universal power electronic interface for EV, HEV, and PHEV applications," IEEE Trans. Power Electron., Vol. 28, No. 12, pp. 5489-5498, Dec. 2013.

[20] M. Kisacikoglu and B. Ozpineci, "EV/PHEV bidirectional charger assessment for V2G reactive power operation," IEEE Trans. Power Electron., Vol. 28, No. 12, pp. 5717-5727, Dec. 2013.

[21] C. Liaw and K. Hu, "On a bidirectional adapter with G2B charging and B2X emergency discharging functions," IEEE Trans. Ind. Electron., Vol. 61, No. 1, pp. 243-257, Jan. 2014

[22] F. Caricchi, F. Crescimbini, F. Giulii Capponi, and L. Solero, "Study of bi-directional buck-boost converter topologies for application in electrical vehicle motor drives," Applied Power Electronics Conference and Exposition, 1998. APEC'98. Conference Proceedings 1998, Thirteenth Annual. IEEE, Vol. 1, pp. 287-293, 1998.

[23] S. Waffler and J. W. Kolar, "A novel low-loss modulation strategy for high-power bidirectional buck boost converters," IEEE Trans. Power Electron., Vol. 24, No. 6, pp. 1589-1599, 2009.

[24] A. Stupar, T. Friedli, J. Minibock, and J. W. Kolar, "Towards a 99\% efficient three-phase buck-type PFC rectifier for 400-V DC distribution systems," IEEE Trans. Power Electron, Vol. 27, No. 4, pp. 1732-1744, Apr. 2012.

[25] B. Wang and G. Venkataramanan, "Analytical modeling of semiconductor losses in matrix converters," Power Electronics and Motion Control Conference, 2006. CES/IEEE 5th International, IEEE, Vol. 1, pp. 1-8, 2006.

[26] Xiong, Yali, S. Sun, H. Jia, P. Shea, and Z. J. Shen, "New physical insights on power MOSFET switching losses," IEEE Trans. Power Electron., Vol. 24, No. 2, pp. 525-531, Feb. 2009.
[27] W. Choi, S. Young, D. Son, S. Shin, D. Hyun, "Consideration to minimize power losses in Synchronous Rectification," Power Electronics and ECCE Asia (ICPE \& ECCE), 2011 IEEE 8th International Conference on, pp. 2899-2905, 2011.

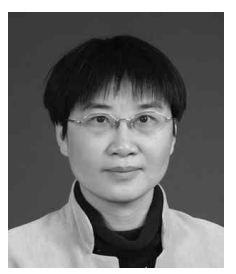

Mei Su was born in Hunan, China, 1967. She received her B.S., M.S. and Ph.D. degrees from the School of Information Science and Engineering, Central South University, Changsha, China, in 1989, 1992 and 2005, respectively. Since 2006, she has been a Professor with School of Information Science and Engineering, Central South University. Her current research interests include matrix converters and wind energy conversion systems.

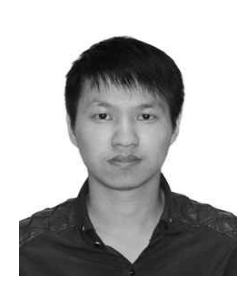

Hua Li was born in Zhejiang, China, in 1989. He received his B.S. degree in Automation from Central South University, Changsha, China, in 2012, where he is presently working toward his M.S. degree in Electrical Engineering. His current research interests include matrix converters and $\mathrm{ac} / \mathrm{dc}$ converters.

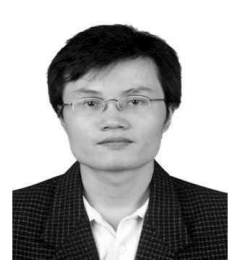

Yao Sun was born in Hunan, China, in 1981. He received his B.S., M.S. and Ph.D. degrees from the School of Information Science and Engineering, Central South University, Changsha, China, in 2004, 2007 and 2010, respectively. He has been an Associate Professor with the School of Information Science and Engineering, Central South University. His current research interests include matrix converters, micro-grid and wind energy conversion systems.

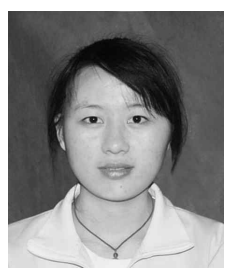

Wenjing Xiong was born in Hunan, China, in 1991. She received her B.S. degree in Automation from Central South University, Changsha, China, in 2012, where she is presently working toward her Ph.D. degree in Electrical Engineering. Her current research interests include power electronics and power transmission. 